\title{
A QUANTITATIVE ANALYSIS OF PRICING BEHAVIOR IN CALIFORNIA'S WHOLESALE ELECTRICITY MARKET DURING SUMMER 2000
}

\author{
Paul Joskow \\ Edward Kahn \\ Working Paper 8157 \\ http://www.nber.org/papers/w8157 \\ NATIONAL BUREAU OF ECONOMIC RESEARCH \\ 1050 Massachusetts Avenue \\ Cambridge, MA 02138 \\ March 2001
}

The views expressed herein are those of the authors and not necessarily those of the National Bureau of Economic Research.

(C) 2001 by Paul Joskow and Edward Kahn. All rights reserved. Short sections of text, not to exceed two paragraphs, may be quoted without explicit permission provided that full credit, including $($ ) notice, is given to the source. 
A Quantitative Analysis of Pricing Behavior in California's Wholesale Electricity Market During Summer 2000

Paul Joskow and Edward Kahn

NBER Working Paper No. 8157

March 2001

\begin{abstract}
We simulate competitive benchmark wholesale prices for electricity in California during the summer of 2000, taking account of changes in natural gas prices, electricity demand, and imports of electricity from other states during this time period. We also examine the impact of changes in the prices of NOx emissions permits on estimated competitive benchmark prices for electricity. The competitive benchmark prices are then compared to actual prices. A significant fraction of the changes in wholesale electricity prices in California during Summer 2000 can be explained by these four factors. The impact of higher NOx permit prices, and their interaction with reduced imports into California, have a particularly large impact on competitive benchmark prices. However, during June, July and August a large unexplained difference between actual prices and competitive benchmark prices remains. We tentatively attribute this difference to supplier market power and related market imperfections. We then examine whether there is evidence of strategic behavior by suppliers during the highest priced hours during the summer. Evidence of supply withholding --exercise of market power --- during these hours is identified.
\end{abstract}

Paul Joskow

Department of Economics

Massachusetts Institute of Technology

Cambridge, MA

and NBER
Edward Kahn

Analysis Group/Economics

San Francisco, CA 


\title{
A Quantitative Analysis of Pricing Behavior In California's Wholesale Electricity Market During Summer 2000
}

\author{
Paul Joskow ${ }^{*}$ and Edward Kahn ${ }^{* *}$
}

January 15, 2001

\section{Introduction}

During the summer of 2000, wholesale electricity prices in California were nearly $500 \%$ higher than they were during the same months in 1998 or 1999. This explosion of prices was unexpected $(\mathrm{CEC}, 2000)$ and has called into question whether electricity restructuring will bring the benefits of competition promised to consumers. Federal and State government officials have initiated investigations and issued reports about the behavior and performance of California's wholesale electricity market. ${ }^{1}$ Unlike previous price spikes observed in other US wholesale electricity markets, the California experience has not been a transient phenomenon of a few days' duration, but a persistent series of events lasting from June through September. ${ }^{2}$

The purpose of this paper is to examine the factors that explain this increase in wholesale electricity prices. There were a number of changes in supply and demand

\footnotetext{
* Elizabeth and James Killian Professor of Economics and Management, Massachusetts Institute of Technology, Cambridge, MA.

${ }^{* *}$ Analysis Group/Economics, San Francisco, CA.

We appreciate the comments of Harold Ray, Kevin Cini, Gary Stern, and Nader Mansour. Matt Barmack, Donna Lau and Virginia Perry-Failor provided excellent research assistance. This paper is based on research commissioned by Southern California Edison Company. Professor Joskow also acknowledges support for his research on competitive electricity markets from the MIT Center for Energy and Environmental Policy Research.

1 Reports include FERC Staff Report (2000), Kahn and Lynch (2000), California Independent System Operator Department of Market Analysis (2000), California Power Exchange Corporation Compliance Unit (2000) among others.

${ }^{2}$ FERC (1998) gives a detailed account of price spikes in Midwestern markets in 1998. Price spikes in the Eastern US during 1999 were related to reliability problems of various kinds (DOE, 2000). Prices in California remained remarkably high in October and November and then reached unprecedented levels during December 2000. The latter part of this period was also accompanied by an order of magnitude increase in gas prices, the evaporation of imports from the Northwest, a large fraction of California's generating capacity was unavailable to supply due to planned or forced outages, some of which were mandated by environmental regulators, new regulatory interventions, and utility credit problems that may have made some suppliers reluctant to supply voluntarily. It is clear that by late 2000, the normal functioning of the wholesale electricity markets had completely broken down. The analysis reported here does not cover the post-September 2000 period, however.
} 
conditions in 2000 that would suggest that prices should have been expected to increase from the previous years: natural gas prices increased, demand increased, and power imports available to California decreased in 2000 compared to 1998 and 1999. The first objective of this paper is to determine how much of the observed price increases can be explained by these three "market fundamentals," assuming that the wholesale power market is perfectly competitive. We do so by simulating competitive benchmark prices given these supply and demand factors prevailing over the summer of 2000 and then compare the simulated competitive benchmark prices with the actual prices observed. We find that while these three supply and demand factors can explain a portion of the observed increase in prices, there is still a large gap between the observed prices and simulated competitive benchmark prices.

The second objective of this paper is to determine whether and how much of this residual can be explained by the prices of tradeable permits for NOx emissions. These emissions permits must be held by generating plants and other affected sources in the South Coast Air Quality Management District (SCAQMD) pursuant to the Regional Clean Air Initiatives Market (RECLAIM) program. ${ }^{3}$ The prices for these emissions permits increased dramatically during the summer of 2000 compared to earlier periods. Including the emissions permit prices in the supply costs of those generators subject to RECLAIM increases competitive benchmark prices for electricity significantly, especially by the end of the summer 2000. However, even after taking account of NOx permit costs, during most of the summer there remains a large gap between the simulated benchmark prices and actual market prices. We attribute this gap to market power and related market imperfections associated with the structure of California's wholesale electricity markets.

The final objective of this paper is to examine whether our attribution of the observed gap between benchmark competitive prices and actual prices is consistent with available data on supplier behavior. Public data are presently available to examine generator operation on an hourly basis from the Environmental Protection Agency (EPA) through the month of June. Southern California Edison supplied us with information from the WSCC on hourly generation by California plants for the months of June through September. ${ }^{4}$ We show that during high demand periods in California it is profitable for suppliers holding a portfolio of generating units with diverse marginal supply costs to withdraw capacity from the market even under otherwise competitive conditions. Our examination of the data shows that many of the price setting units produced much less energy than could have been produced at marginal costs below observed market clearing prices. This behavior cannot be explained by the demand for ancillary services by the

\footnotetext{
${ }^{3}$ We have not examined air quality regulations that may restrict production through command-and-control regulations. It is our impression that such regulations are not binding in California.

${ }^{4}$ We discuss the comparability of these data sources below. The WSCC data are available to all members of the WSCC for a nominal price. The EPA data are available on the EPA's web site.
} 
CAISO. Therefore, either the units were suffering from unusual operational problems or they were being withheld from the market to increase prices. ${ }^{5}$

A number of previous studies have examined wholesale electricity prices in California and found that there is some evidence of market power, especially during high demand periods. Most of this analysis relies on confidential data available only to the California Independent System Operator (CAISO) or to the California Power Exchange (PX). In addition to extending this kind of analysis to the summer of 2000, with its extraordinarily high prices, our paper provides three innovations. First, it relies on data which are generally available to the public rather than on confidential data available only to the CAISO or PX and their respective market surveillance committees. Second, previous analyses of wholesale market prices in California have not systematically taken into account the prices for NOx emissions permits which generating plants located in the Los Angeles area must hold to cover there emissions of NOx Third, we extend the analysis of pricing behavior to include an examination of the output supplied by generators in California to determine whether generating plants that should be economical to operate when prices are high are being systematically withheld from the market, consistent with attributing the gap between competitive benchmark prices and actual prices to the exercise of market power.

\section{Background}

California's current wholesale market institutions began operating in April 1998 after four years of debate about electricity sector restructuring and the design and creation of complex new wholesale market institutions. Under California's electricity restructuring and deregulation program, wholesale market prices would be "market-based." A non-profit

\footnotetext{
${ }^{5}$ The data available to us are not sufficient to measure supplier withholding behavior by generators located outside of the CAISO. Nor can we measure the control over generation supplies acquired by wholesale market aggregators or their bidding and supply behavior. Yet, as we will demonstrate, net imports into California can have significant effects on market-clearing prices. These imports declined significantly in Summer 2000 compared to Summer 1999 and wholesale marketers were likely to have been active participants as buyers and sellers in the California markets. It is possible that generators, or wholesale market aggregators, controlling supplies from generating units outside of California may also have the incentive and ability to increase wholesale market prices in California (and the rest of the WSCC). Accordingly, a complete and definitive picture of wholesale market behavior and performance in California this past summer, and the effects of strategic behavior by suppliers with market power, requires an analysis of demand and supply conditions in those portions of the WSCC that historically have provided the bulk of the net supplies to California. Such an analysis should also take account the control over generation supplies accumulated by wholesale marketers operating in the WSCC. The information necessary to perform this analysis is neither publicly available nor available to the CAISO. This is the area where additional data collection and appropriate empirical analysis by responsible regulatory agencies can provide value-added to the extensive analysis of market behavior and performance of California suppliers that has been completed over the last two years.

${ }^{6}$ Technically, wholesale prices have not been "deregulated." They are subject to regulation by the Federal Energy Regulatory Commission (FERC) pursuant to the Federal Power Act. The Federal Power Act requires FERC to approve wholesale prices only if they are "just and reasonable." Traditionally, FERC fulfilled its obligations under the Federal Power Act by using various cost benchmarks to cap wholesale prices (Joskow (1989). During the 1990s FERC began to grant suppliers "market-based pricing authority"
} 
California Independent System Operator (CAISO) was created to operate the transmission networks owned by the state's Investor Owned Utilities (IOU) and a Power Exchange (PX) was created to operate day-ahead hourly auction markets for wholesale electrical energy. ${ }^{7}$ CAISO also operates hourly auction markets for operating reserves (ancillary services), for energy to balance supply and demand on short notice, and for generating capacity that can be used to manage congestion. All supply from generators selling into the CAISO control area and all demand by "load serving entities" located in the CAISO control area must ultimately be physically scheduled with or dispatched by CAISO.

The suppliers of generating capacity to serve demand in California are composed of in-state generators and out-of-state generators. The in-state generators consist of four nuclear power plants, hydro-electric plants that are located primarily in Northern California, gas-fired steam and peaking turbines, and cogenerators and other generation sources that are "Qualifying Facilities" (QFs) under the Public Utility Regulatory Policy Act of 1978 (PURPA). About half of the conventional in-state generating capacity is accounted for by gas-fired steam and peaking units and these units are the marginal supply sources during most hours in the summer when electricity demand in California is highest. It is fairly easy to measure the marginal costs of these units since their thermal efficiencies at different output levels are well known and spot market prices for natural gas are available from a variety of sources. No new generating capacity has entered the California market since it began operating in 1998 and most of the gas-fired capacity dates back to the 1960s and 1970s.

During the summer months, the marginal supply resource that clears supply and demand is typically a conventional steam or combustion turbine unit fueled by natural gas or oil. Figure 1 depicts the marginal cost curves for this gas-fired generating capacity in the ISO's control area, assuming that the price of gas is either $\$ 2.50 / \mathrm{Mcf}$ (as in 1999) or \$6/Mcf (as in late summer 2000). These marginal cost curves can be thought of as the "top" of the CAISO areas's competitive generation supply curve during the summer months. During summer hours a competitive market would clear somewhere along these supply curves. Changes in natural gas prices shift the supply curve up or down and, other things equal, competitive market prices would move up or down along with the changes in gas prices. Changes in demand move the equilibrium competitive price along this supply curve so that competitive prices increase directly with demand. As we shall discuss, tradeable permits for NOx emissions increase and "twist" the marginal cost curve depending on the price of NOx credit and differences in emissions rates across generating units, so that the competitive price for electricity increases directly with NOx permit prices. In addition, at high demand levels, the competitive supply curve is much steeper with a NOx permit trading system than without one. This is the case because the generating units with the highest emissions rates produce as much as 50 times more NOx per unit of electricity output than those with the lowest emissions rates while the difference in marginal fuel costs between the most efficient and least efficient generating unit is only a factor of about two.

if they could demonstrate that they did not have market power (Joskow 2000). This is the basis for "deregulation" of wholesale market prices in California.

${ }^{7}$ The PX also operates "hour-ahead" and monthly block forward markets, but they are of little quantitative or financial significance and will not be discussed further here. 


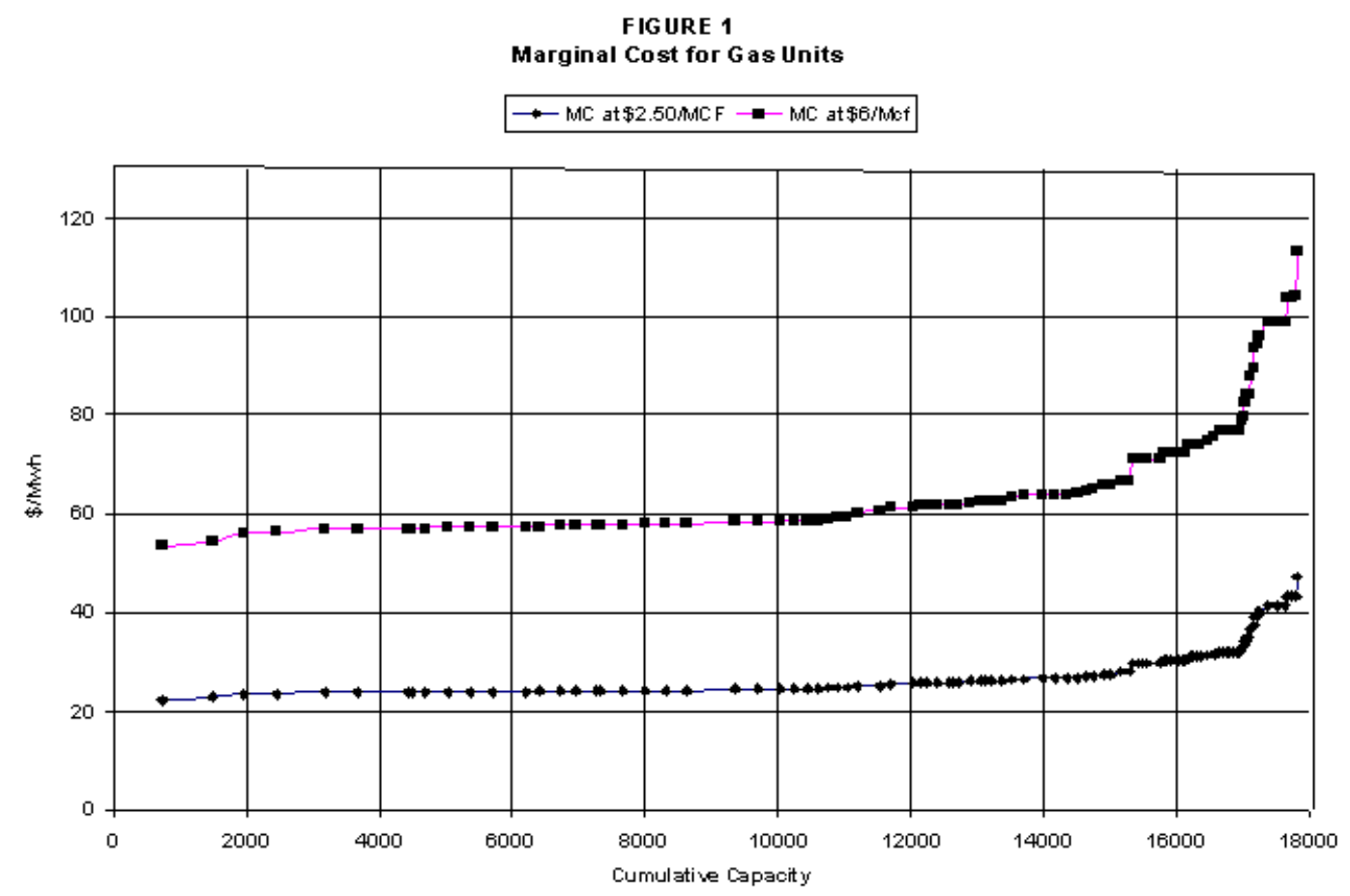

Until 1998 and 1999, the 18,000 Mw of gas-fired capacity in the CAISO's control area was owned by the three vertically integrated IOUs. Under California's restructuring program, these utilities were required to sell this capacity to independent companies or New Generation Owners (NGOs). Most of this capacity was ultimately sold to five out-of-state companies with large national unregulated power plant businesses. The nuclear and hydroelectric capacity, and the high-price contracts with QFs, were retained by California's three IOUs. This amounts to about half of the original in-state generating capacity originally owned by or contracted for by these utilities prior to restructuring. The hydroelectric capacity retained by the IOUs has limited energy production capabilities over the course of the year dictated by reservoir storage capacity, water runoff, and water release constraints.

California has historically imported large quantities of electricity from neighboring states. During the 1960s and 1970s long high voltage transmission lines were built from California to the Northwest and the Southwest to facilitate transfers of energy to and from California. California typically imports electricity from the Southwest (primarily nuclear, coal and gas-fired capacity) all year round and imports large amounts of electricity from the Northwest (primarily stored hydro) during the Spring and Summer months. During the late Fall and Winter months California historically exported some electricity to the Northwest, primarily during off-peak hours. The generating capacity in the Southwest and the Northwest available to sell electricity to California is primarily owned by vertically integrated IOUs or Federal Power Marketing agencies. These entities in turn have legal or contractual obligations to supply their local "native loads" and can only sell any excess supplies to 
California. One of California's investor-owned utilities (Southern California Edison) owns nuclear and coal capacity in the Southwest and has contractual entitlements to some hydroelectricity produced at Hoover Dam. Though the nuclear and coal plants have been put up for sale at auction and winning bidders for some of this capacity have been chosen, this capacity continued to be controlled by Southern California Edison during the period we studied.

Electricity demand in California is highest during the summer months and lowest in the Spring and Fall months. It is highest during the day and lowest at night and on weekends. The peak demand in the CAISO control area in 1999 was about 43,000 Mw. Demand fell to less than 20,000 Mw during some off-peak periods. California's restructuring program included a "retail competition" option which permitted all retail consumers to arrange for their power supplies with an unregulated retail electricity service provider (ESP) of their choice. ESPs arrange for power supplies in the wholesale market and deliver it to consumers over one of the utilities distribution networks. The distribution and transmission charges are regulated separately based on cost by the California Public Utilities Commission (CPUC) and FERC respectively. Consumers who do not voluntarily choose an ESP continue to receive "default service" from one of the three IOUs as they always have. About $90 \%$ of the retail demand continued to be supplied by the utilities during 2000 .

It is particularly important to note for our purposes that the short run elasticity of demand for electricity in California is close to zero and is almost completely unresponsive to swings in hourly prices since few consumers have hourly recording meters or the communications and control equipment to interact directly with the wholesale market. Moreover, during the time period we study, while wholesale prices were effectively deregulated, retail prices for generation service continued to be regulated based on a predetermined retail price of roughly $\$ 60 / \mathrm{Mwh}$. When this cap was set in 1996 , it was expected that wholesale prices would be far below this figure (about $\$ 30 / \mathrm{Mwh}$ ) for several years and that the "head room" between the $\$ 60 /$ Mwh retail price and the expected lower wholesale price would allow the utilities to recover quickly the costs of nuclear plants and QF contracts whose total costs were thought to be higher than their competitive market values in the wholesale market ("stranded costs"). As soon as these stranded costs were recovered retail prices for electric energy were then supposed to be deregulated and "fall" to reflect wholesale market conditions. The year 2000 led to some surprises on this front.

California's restructuring and competition rules required the IOUs to serve all of their default service demand from the PX and ISO spot energy markets. They were also required to bid all of their remaining generation supplies into the PX and ISO spot markets. Independent generation suppliers and non-utility demands were not required to deal through the PX or ISOs markets, but could instead enter into bilateral contracts and self-supply ancillary services. Since the utilities retained responsibility for such a large fraction of the demand, most of the wholesale trade in electricity took place either in the PX's day-ahead market or in the ISO's real time balancing market.

Our analysis of prices focuses on the hourly day-ahead unconstrained prices observed in the PX during the summer of 2000. We focus on the PX because it was the venue where the bulk of the energy was traded. Moreover, there appears to be reasonably efficient arbitrage between the PX market, the bilateral day-ahead market (Joskow, 2000), and the real time market ( Borenstein, Bushnell, Knittel and Wolfram, 2000). We focus on unconstrained 
prices (that is, pre-congestion management) for simplicity, though there is relatively little significant transmission congestion during summer of 2000. We do take congestion into account in our analysis of supplier withholding.

Table 1 displays the average hourly volume weighted prices for each month from April 1998 through December 2000. The fourth column of the table is a comparable set of forecast prices for year 2000 published by the California Energy Commission in March 2000. The Table indicates that PX prices were roughly in line with expectations during 1998 and 1999 and the first four months on 2000. In May 2000 prices began to rise and then rose to unprecedented levels in June. Prices moderated somewhat in July and then jumped significantly in August before moderating a bit again in September. Prices throughout the summer months of 2000 were four to five times higher than in 1998 and 1999 and the CEC's projections for 2000 . While we have not yet analyzed the post-September prices, it should be 
TABLE 1

\section{CALIFORNIA PX DAY-AHEAD PRICES \\ (\$/Mwh:Weighted Averages 7 x 24)}

\begin{tabular}{|c|c|c|c|c|}
\hline & 1998 & $\underline{1999}$ & $\underline{2000}$ & $\underline{2000(\mathrm{CEC})^{8}}$ \\
\hline January & - & 21.6 & 31.8 & 27.7 \\
\hline February & - & 19.6 & 18.8 & 24.1 \\
\hline March & - & 24.0 & 29.3 & 23.3 \\
\hline April & 23.3 & 24.7 & 27.4 & 20.0 \\
\hline May & 12.5 & 24.7 & 50.4 & 18.5 \\
\hline June & 13.3 & 25.8 & 132.4 & 18.8 \\
\hline July & 35.6 & 31.5 & 115.3 & 28.0 \\
\hline August & 43.4 & 34.7 & 175.2 & 40.9 \\
\hline September & 37.0 & 35.2 & 119.6 & 45.3 \\
\hline October & 27.3 & 49.0 & 103.2 & 32.2 \\
\hline November & 26.5 & 38.3 & 179.4 & 31.6 \\
\hline December & 30.0 & 30.2 & 385.6 & 30.7 \\
\hline AVERAGE & 30.0 & 30.0 & 115.0 & 28.5 \\
\hline
\end{tabular}


clear that prices did not return to "normal" levels and exploded again in December. There are a number of unusual events that affected California's electricity markets after October that make this period difficult to analyze; an order of magnitude increase in gas prices during December, gas shortages, changes in market rules, a large quantity of plant outages, utility credit problems, and other factors that make this latter period difficult to analyze. Our analysis focuses on PX market clearing prices during the May through September 2000 period.

It should be noted that the prices in Table 1 do not reflect "fully unregulated" wholesale prices. Until July there was a $\$ 750 / \mathrm{Mwh}$ cap on prices. This cap was reduced to $\$ 500 / \mathrm{Mwh}$ during July and then to $\$ 250 / \mathrm{Mwh}$ in early August. The $\$ 500 / \mathrm{Mwh}$ and then $\$ 250 /$ Mwh cap were binding during many hours in August and September. 9

\section{Method for Estimating Competitive Benchmark Prices with Public Data}

In this section we estimate competitive wholesale market benchmark prices and compare these benchmark prices to the prices that were actually observed. These benchmark prices are for sales of energy in the day-ahead market. (Generators earn additional revenues from supplying ancillary services to the ISO. These revenues are especially important for covering the fixed costs of peaking units that supply energy infrequently but serve as operating and replacement reserves much more frequently.) The more the observed price exceeds the competitive benchmark price, the more one can presume that either market power was being exercised or some other source of market imperfection has interfered with the competitive interplay of supply and demand. The competitive price benchmark that we utilize is the short run marginal cost of supplying electricity from the last unit that clears the market in each hour. Comparing realized prices with marginal supply costs in this way is a widely accepted method for measuring the presence of market power, and is especially useful for examining market prices in commodity markets with homogeneous products like spot electricity markets. ${ }^{10} \mathrm{We}$ recognize that small departures from ideal competitive conditions do not necessarily imply that there is sufficient market power to be of policy concern; many markets that are not subject to price control are imperfectly competitive. Moreover, any empirical analysis of pricing behavior is subject to some degree of uncertainty. However, this approach allows us to quantify how far realized market prices depart from competitive benchmark prices and provides a metric which policymakers can utilize to come to a

\footnotetext{
${ }^{9}$ Technically, the cap was on prices in the ISO's real time market. However, since it would have been irrational to pay more than the real time market price cap in the day-ahead market, this became the effective cap on day-ahead prices in the PX as well. During emergency situations, it was widely known that the ISO would pay more than the price cap for supplies and this probably had the effect of creating more emergencies as generators withheld scheduling supplies day-ahead or hour-ahead in the hope of getting higher prices from the ISO through a last-minute "out of market" sale.

${ }^{10}$ Economists frequently use the "Lerner Index" to measure market power. The Lerner Index is calculated by taking the difference between realized prices and marginal supply costs and dividing by the realized prices: $\mathrm{L}=(\mathrm{P}-\mathrm{MC}) / \mathrm{P}$. In a perfectly competitive market the Lerner Index is zero and in a pure monopoly it is equal to one. The more the Lerner Index differs from zero, the greater is measured market power. See Carlton and Perloff (1999), pages 92, 264, and 269 and Tirole (1988), pages 66, 70, 80 219-220, and 222.
} 
judgment about whether the gap between competitive benchmark prices and actual prices is so large that regulatory interventions are justified.

This approach to measuring market power in wholesale electricity markets was pioneered by Wolfram (1999) in her study of the electricity market operating in England and Wales. The same approach has been applied previously in studies of the California market (Borenstein, Bushnell and Wolak, 2000; Wolak, Nordhaus and Shapiro, 2000; and Hildebrandt, 2000). We will discuss these earlier studies of market power in California's wholesale electricity markets further below, though we note here that these studies relied on confidential data to which we do not have access.

The only published estimates of the competitive benchmark prices for energy in California's wholesale electricity market have been made by researchers with access to confidential CAISO data. In particular, Borenstein, Bushnell and Wolak (hereafter BBW) and Wolak, Nordhaus and Shapiro (hereafter WNS) adopt a methodology that takes advantage of CAISO data to simulate the competitive wholesale market price for energy in every hour. ${ }^{11}$ Hildebrandt (2000) also makes such estimates, using a methodology described in CAISO (2000). We also refer to Hildebrandt's approach, but because the method is described in less detail, we emphasize BBW in what follows. We describe BBW's procedure briefly and then discuss how approximations must be made when the confidential data they rely upon are not available. Because WNS use the same methods as BBW, but they are described in detail only in BBW, all of our discussion of WNS procedures refers to BBW.

We begin by summarizing how BBW estimate the output and competitive benchmark price for the different types of resources that serve demand in California. BBW rely on CAISO settlement data for the hourly output of must-take generation, geothermal and hydro production. ${ }^{12}$ The sum of the output from these resources generally exceeds 20,000 MW. CAISO peak loads are typically in the range of 30,000 to 45,000 MW. Imports and California in-state fossil generation make up the difference. Net imports are not used directly by BBW. Instead they adjust observed net imports to reflect competitive responses to price. SCE's share of Mohave is metered as must-take generation and is reflected in the settlements data. It is therefore treated as in-state production by BBW. Production from other plants owned by in-state utilities apparently is classified as imports. If observed market prices are above the competitive level, then observed imported quantities will be above the level that would be obtained under lower competitive prices. BBW rely upon adjustment bids to characterize the price

\footnotetext{
${ }^{11}$ Sheffrin (2000), discussed below, also has an estimate of the "competitive benchmark" price, but there is no discussion of the procedure used to construct it.

${ }^{12}$ Must-take generation consists primarily of nuclear and Qualifying Facilities under PURPA. BBW argue that the behavior of geothermal and hydro owners is competitive during the period they examine and so they use the hourly settlements data on that behavior in their calculation.
} 
responsiveness of imports. ${ }^{13}$ They then simulate a dispatch of the in-state fossil generation included within the CAISO grid against the remaining demand. To take account of random forced outages, BBW use a Monte Carlo procedure, taking draws from the outage distribution based on public data.

Our procedure differs from BBW because it must be adapted to the limitations of public data, and our goal of making relatively simple, but robust estimates. We describe each major element of our analytical approach below.

\section{Load Slices}

We are constrained to analyze months as homogeneous periods because we only have hydro data available on a monthly basis (see below). Within each month, we rely, for simplicity, on 10 load periods. We segment the hourly demand in each month into 10 load deciles. Within each decile, we look at the mean load in the decile and use the intersection of that demand with the supply curve for the month to estimate the mean price for that decile. We add 10\% to each demand level reflecting the CAISO's demand for ancillary services capacity. ${ }^{14}$

\section{Hydro}

Public data on hydroelectric output is only available on a monthly basis. EIA Form 759 gives output at the unit level. These data allow us to separate units that are dispatched by the CAISO from other California hydro units, but provide no information about how to allocate the energy from the relevant units to different time periods. We have tried assigning this energy to periods within each month using different algorithms. These algorithms assign energy to higher demand periods up to a maximum subject to the constraint that every period receive some minimum amount of hydro energy. Our base case relies on an algorithm which limits the amount of hydro energy in each period to a minimum of 60 percent of the amount that would be assigned to each hour if hydro energy were spread evenly throughout the month and a maximum of 8,000 MW. This is a conservative procedure that may tend to allocate less hydro capacity to high demand periods than actually occurs, leading to higher estimates of competitive peak period prices for electricity.

The 8,000 MW hydro maximum is plausible since it represents approximately two thirds of the hydro capacity inside of the ISO. ${ }^{15}$ Because of long-term contracts and agreements, such as those between WAPA and many CA municipal utilities, not all hydro capacity is available to meet peak demand. 8,000 MW is approximately the

\footnotetext{
${ }^{13}$ Adjustment bids are supply and demand curves representing offers by scheduling coordinators to increase or decrease output at potentially congested interfaces. BBW aggregate these bids over all interfaces on the boundary of the California ISO control area. This information is not publicly available.

${ }^{14}$ Hildebrandt (2000) uses a similar adjustment, representing 3\% for regulation and $7 \%$ for WSCC guidelines on reserves .

${ }^{15}$ Based on EIA Form 860, we count just under 12,000 MW of hydro capacity inside of the ISO including all hydro and pump-storage capacity in California besides that owned by LADWP.
} 
capacity that can be dispatched by SCE and PG\&E and hence is likely to be priceresponsive.

\section{Imports}

Our measure of imports differs slightly from BBW. The settlements data utilized by BBW treat SCE's share of Mohave as must-take generation, and include it as part of in-state production. In contrast, we use the line flow data as posted on the CAISO website. Using line flows treats all out of state production, including that from SCE's Mohave plant as imported.

Otherwise we adopt the BBW philosophy with regard to adjusting imports. They argue that the high observed prices in California would draw in more imports than would occur under lower competitive prices, other things equal. Confidential data on adjustment bids are used to characterize this elasticity. Instead of the transmission bid data, we use data on the ex post realizations of net imports ${ }^{16}$ and PX prices and an assumed elasticity of net imports to impute net imports under marginal cost pricing. In other words, for each period and for every price level $c$, we calculate the amount of infra-marginal net imports as follows:

$$
\operatorname{netimp}(c)=\left(\frac{c}{p_{p x}}\right)^{\eta} \cdot \operatorname{netimp}\left(p_{p x}\right)
$$

where $\eta$ is the elasticity of net imports, $p_{p x}$ is the realized PX price, and netimp $\left(p_{p x}\right)$ is the realized level of net imports at the realized PX price. We have assumed an elasticity of 0.33 . This elasticity is loosely based on BBW's claim that imports would be 5.3 percent lower (p. 30) and prices approximately 15.5 percent lower (p. 33) under marginal cost pricing. Given the imprecision of their elasticity estimates, ${ }^{17}$ an elasticity of 0.33 is well within the range of what they find.

\section{In-state Fossil}

Natural gas costs for weekdays at the Southern California burnertip and at Malin were provided to us by Southern California Edison, from trade publications. We add transport costs to the Malin prices to bring the costs to the burnertip in Northern California. Because we are constrained to a monthly level of analysis, we use monthly averages of these prices. The monthly gas price values used are given in Section 3, where we present results.

We rely upon the Henwood Energy Services Incorporated (HESI) commercially available database for the WSCC to characterize heat rates, capacities, forced outage rates, and variable O\&M costs for instate fossil generators. The heat rate data are consistent with those found in Klein (1998).

\footnotetext{
16 These data are only available beginning in January 1999. For benchmarking purposes, to estimate imports for the last six months of 1998, we use data on realized net imports from the last six months of 1999.

${ }^{17} \mathrm{BBW}$ 's estimate of 5.3 percent has a standard deviation of 8.1 percent.
} 
Forced outages and planned outages are accounted for separately. We take a simplified view of forced outages. We use the HESI data on forced outage rates to reduce, or "derate," the capacity of each generating unit in every load period. Planned outages for maintenance, however, we allocate exclusively to low demand months. Our procedure for scheduling maintenance seeks to equalize the reserve margin across months. This is a common procedure in production simulation modeling, and it reflects standard industry practices. Details are given in the Appendix.

Our methods for reflecting forced outages differ from those of BBW. They use a Monte Carlo simulation of forced outages for instate fossil generation. BBW argue that maintenance decisions for these units are strategic variables and, therefore, they make no estimate of such outages for instate fossil generators. By relying on settlements data for must-take resources, BBW are reflecting both maintenance and forced outages for all of this capacity. In contrast, we apply the outage treatment for instate fossil to must-take resources as well, since we do not have hourly outage information.

\section{RECLAIM NOx RTC Prices}

One factor that can affect competitive market prices for electricity which neither BBW nor the CAISO addresses involves the impact of the air emissions regulatory framework in California. California has extremely stringent air quality regulations. One pollutant of particular concern is nitrogen oxide (NOx). As explained above, regulation of emissions in the Los Angeles area is controlled by the SCAQMD which utilizes the Reclaim Trading Credit (RTC) emissions permit trading program for NOx emissions from electric generating units and other stationary sources. Under this program NOx emissions are regularly reported during pre-established cycle periods. The owners of a source of NOx emissions must reconcile NOx RTC allowances with reported emissions within 60 days of the end of the reporting cycle. ${ }^{18}$ The RTC program resembles the $\mathrm{SO} 2$ permit trading regime authorized under the 1990 Clean Air Act Amendments. ${ }^{19}$

We would expect competitive generation suppliers to include the prices of RTC NOx credits in their bids even if these credits had been previously acquired at much lower prices (or for free). This is the case because these emissions credits could be sold to other affected sources at their market value and thus represent a legitimate competitive market opportunity cost. ${ }^{20}$ RTC allowances had been selling at very low prices (\$1-2/pound) through the early part of 2000. Since most generation in the SCAQMD area emits 1 $\mathrm{lb} / \mathrm{MWh}$ of NOx or less, emissions costs internalized into electricity prices would be \$1$2 / \mathrm{MWh}$ at most during this period. Starting in Spring 2000, however, RTC prices began

\footnotetext{
${ }^{18}$ NOx RTC allowances have expiration dates that correspond to the end of each cycle period.

${ }^{19}$ The SO2 emissions trading program is described in detail by Ellerman et al, (2000).

${ }^{20}$ Obviously, generators which acquired these RTC NOx credits at much lower prices will earn very significant profits as a consequence of the run-up in NOx credit prices and its impact on wholesale electricity prices. Thus, the impact of changes in NOx credit prices on electricity prices in a competitive wholesale market is far larger than it would have been under traditional cost-of-service regulation where consumers would have captured any infra-marginal "rents" associated with changes in NOx credit prices.
} 
to increase substantially. ${ }^{21}$ By June they were nearly $\$ 10 /$ pound. This would add \$10/MWh to MCP most of the time, and much more when gas turbines with much higher emissions rates, e.g., some turbines emit in excess of $6 \mathrm{lb} / \mathrm{MWh}$, are producing electricity. NOx RTC prices continued to climb throughout the summer, rising to around $\$ 35 /$ pound by late August. At these levels, NOx RTC requirements significantly affect price during all hours for which fossil plants in the SCAQMD clear the market, but especially during peak periods when gas turbines are on the margin. Therefore, we decided to add the effects of NOx RTC prices to our estimates.

For most units in SCAQMD that were formerly owned by SCE, we rely on estimates provided to us by SCE based on publicly available data and regulatory filings. For other units we rely on NOx emissions from the HESI databases.

\section{Results}

Table 2 below presents our estimates of the competitive wholesale spot market benchmark prices for May through September 2000. We report a range of prices, reflecting alternative assumptions about NOx RTC prices. Table 2 also displays the actual average day-ahead PX prices during these months of year 2000 for comparison purposes. The data on NOx RTC prices are difficult to interpret for a variety of reasons. There is general agreement that NOx RTC prices were increasing between May and September. Finding an appropriate price for each month requires that we interpret the data from SCAQMD carefully. We give a full discussion of the choices we have made in the Appendix. Table 2 indicates in bold the benchmark wholesale market price associated with our choice of the most appropriate NOx RTC price for each month.

Table 2. Competitive Counterfactual at Different RTC Costs (2000)

\begin{tabular}{|l|l|rrrrr|rr|}
\hline & $\begin{array}{l}\text { Average } \\
\text { PX price } \\
\text { (\$/MWh) }\end{array}$ & \multicolumn{5}{|c|}{$\begin{array}{c}\text { Competitive Benchmark Prices } \\
\text { (\$/MWh) }\end{array}$} & \multicolumn{2}{|c|}{$\begin{array}{l}\text { Average gas prices } \\
\text { (\$/MMBtu) }\end{array}$} \\
\hline Month & & & \multicolumn{4}{|c|}{ Assumed NOx price } & & \\
\hline May & 47.23 & $\mathbf{4 7 . 0 5}$ & 53.55 & 58.40 & 64.82 & 68.17 & 3.77 & 4.11 \\
June & 120.20 & 55.19 & $\mathbf{6 2 . 6 0}$ & 70.12 & 77.78 & 81.85 & 4.59 & 4.99 \\
July & 105.72 & 53.38 & 61.49 & $\mathbf{6 7 . 9 8}$ & 75.52 & 79.09 & 4.35 & 4.97 \\
August & 166.24 & 71.96 & 87.01 & 102.49 & 114.13 & $\mathbf{1 2 1 . 5 0}$ & 4.84 & 5.69 \\
September & 114.87 & 73.72 & 83.41 & 91.59 & 99.99 & $\mathbf{1 0 4 . 3 6}$ & 5.88 & 6.64 \\
\hline
\end{tabular}

It is clear from Table 2 that there is a significant gap between the competitive benchmark prices that we estimate and actual market prices in June, July and August

\footnotetext{
${ }^{21}$ We have not analyzed why NOx RTC credit prices increased so much during the summer of 2000 or whether the observed price increases are consistent with competitive behavior in the RTC credit market. A careful analysis of behavior and performance of the RTC credit market would also be a worthwhile undertaking.
} 
2000. The gap for September is much smaller and is within the error bounds of our methodology. We want to emphasize that this gap between competitive benchmark prices and actual market prices takes into account the effects of gas prices, load levels, imports levels, and NOx credit prices; the "market fundamentals" that have often been identified as contributing to higher prices in summer 2000 than in summer 1999. It is also important to recognize that if NOx credit prices had remained at 1999 levels, competitive benchmark prices would have been very significantly reduced. We believe that the estimated price gap is large enough to provide credible evidence that market power or other market imperfections lead to a significant increase in prices above competitive levels during summer 2000. At the very least, this finding makes it clear that additional analysis of generator and marketer behavior based on data which are not now available to us is warranted.

Our estimates of competitive benchmark prices are very similar to those obtained in other studies using similar techniques and confidential data to which we do not have access. BBW does not include the cost of RTC allowances in their estimates. Given the very low level of RTC prices until the Spring of 2000, these costs would not have a significant impact the estimates made in BBW, since these only extend through September, 1999. In the Appendix we compare the results from applying our approach with those reported by BBW for January-September 1999, ignoring NOx RTC prices.

Hildebrandt's estimates of the May-September competitive prices are similar to our estimates in the zero RTC price case. For May, June and July our estimates are within $\$ 1 / \mathrm{MWh}$ of his. For August and September our estimate is $\$ 4-8 / \mathrm{MWh}$ higher.

\section{Sensitivity Cases}

One use of the framework that we have applied to develop competitive benchmark prices is to examine hypotheses about the effects of key variables on competitive market prices. Here we examine three significant issues; (1) the effect on wholesale prices of reductions in net imports between 1999 and 2000, (2) the effects on wholesale prices of installing NOx control equipment on the five most polluting gas turbines in the SCAQMD, and (3) the effect of retrofitting NOx controls both on the gas turbines as well as on all steam generators in SCAQMD.

First, we look at the effect of reductions in net imports between 1999 and 2000 on the competitive benchmark wholesale market prices for electricity estimated using our approach. Many commentators have remarked on the significant decline in net imports between summer 1999 and summer 2000. Table 3 shows the mean difference in actual net imports from year to year. It also compares the estimated benchmark price before considering effects of RTC credit prices (i.e., based on the zero RTC credit price column in Table 2) with our estimate of what the competitive benchmark price would have been if the 1999 level of imports had occurred. It is clear that prices are higher in Summer 2000 as a result of lower net imports, but if NOx emissions were not an issue, the impact of reduced imports alone accounts for a relatively small fraction of the actual increase in wholesale prices from Summer 1999 to Summer 2000. As NOx RTC prices rise toward the end of the summer, the reduced level of imports becomes a much more important factor in explaining wholesale price increases. 
Table 3. Net Import Sensitivity

\begin{tabular}{|c|c|c|c|c|c|}
\hline & June & July & August & September \\
\hline \multirow{2}{*}{\multicolumn{2}{|c|}{\begin{tabular}{|l|}
1999 actual average hourly net imports (MWh) \\
2000 actual average hourly net imports (MWh)
\end{tabular}}} & 7426 & 8146 & 7874 & 8323 \\
\hline & & 4973 & 4250 & 2892 & 4472 \\
\hline \multirow{2}{*}{$\begin{array}{l}\text { MCP with } 1999 \text { net imports (\$) } \\
\text { MCP with } 2000 \text { net imports (\$) }\end{array}$} & \multirow[t]{2}{*}{ NOx $\$ 0 / \mathrm{lb}$} & 53.35 & 48.24 & 60.83 & 63.56 \\
\hline & & 55.19 & 53.38 & 71.96 & 73.72 \\
\hline \multirow{2}{*}{$\begin{array}{l}\text { MCP with } 1999 \text { net imports (\$) } \\
\text { MCP with } 2000 \text { net imports (\$) }\end{array}$} & \multirow[t]{2}{*}{$\mathrm{NOx} \$ 10 / \mathrm{lb}$} & 60.52 & 49.64 & 65.59 & 66.47 \\
\hline & & 62.60 & 61.49 & 87.01 & 83.41 \\
\hline \multirow{2}{*}{$\begin{array}{l}\text { MCP with } 1999 \text { net imports (\$) } \\
\text { MCP with } 2000 \text { net imports (\$) }\end{array}$} & \multirow[t]{2}{*}{$\mathrm{NOx} \$ 20 / \mathrm{lb}$} & 63.87 & 51.11 & 72.89 & 68.10 \\
\hline & & 70.12 & 67.98 & 102.49 & 91.59 \\
\hline \multirow{2}{*}{$\begin{array}{l}\text { MCP with } 1999 \text { net imports (\$) } \\
\text { MCP with } 2000 \text { net imports (\$) }\end{array}$} & \multirow[t]{2}{*}{ NOx $\$ 30 / 1 b$} & 69.80 & 52.59 & 69.67 & 68.86 \\
\hline & & 77.78 & 75.52 & 114.13 & 99.99 \\
\hline \multirow{2}{*}{$\begin{array}{l}\text { MCP with } 1999 \text { net imports (\$) } \\
\text { MCP with } 2000 \text { net imports (\$) }\end{array}$} & \multirow[t]{2}{*}{$\mathrm{NOx} \$ 35 / \mathrm{lb}$} & 72.64 & 52.94 & 70.87 & 69.09 \\
\hline & & 81.85 & 79.09 & 121.50 & 104.36 \\
\hline
\end{tabular}

Next we examine the potential effect on wholesale market prices of additional NOx controls applied to the five most polluting gas turbines in SCAQMD. Engineering estimates of the cost and performance of water injection retrofits for gas turbines suggest that $65 \%$ reduction in emission rates are achievable for costs of less than $\$ 1$ million per unit. $^{22}$ We illustrate the dramatic effect that such reductions would have had on wholesale electricity prices in August 2000, when these units set market-clearing prices for electricity during high load periods. With these modest NOx control expenditures, wholesale market prices would have been \$24/MWh lower in August 2000, assuming $\$ 35 / 1 b$ RTC prices. At lower loads, such as in the months of June, July and September, the effect is half as large.

Table 4 shows the effect of NOx controls on the gas turbines and the installation of SCRs on steam units by load decile for August. Table 5 shows the impact of both kinds of controls on average benchmark prices for June-September for various NOx RTCs prices. This enhanced NOx control initiative, including both emissions controls on gas turbines and the installation of SCRs on steam units, further reduces benchmark competitive prices. Overall, these NOx emissions controls reduce benchmark competitive prices by over $\$ 17 / \mathrm{MWh}$ on average during June through September $2000{ }^{23}$

\footnotetext{
${ }^{22}$ Overbuin (1994) gives the performance data on tests for the Alamitos gas turbine. This is a representative case. Cost estimates come from C. Alcaino, SCE.

${ }^{23}$ Using the bold figures in Table 4 to identity the changes in RTC prices over the period, we get benchmark price reductions of $\$ 5$ in June, $\$ 9$ in July, \$34 in August and \$21 in September.
} 
This translates into a reduction in payments by buyers to electricity suppliers of roughly $\$ 1.5$ billion during the June through September period. ${ }^{24}$

Table 4. Comparison of August Benchmark Prices With Different NOx Controls: RTC Costs @ \$35/lb

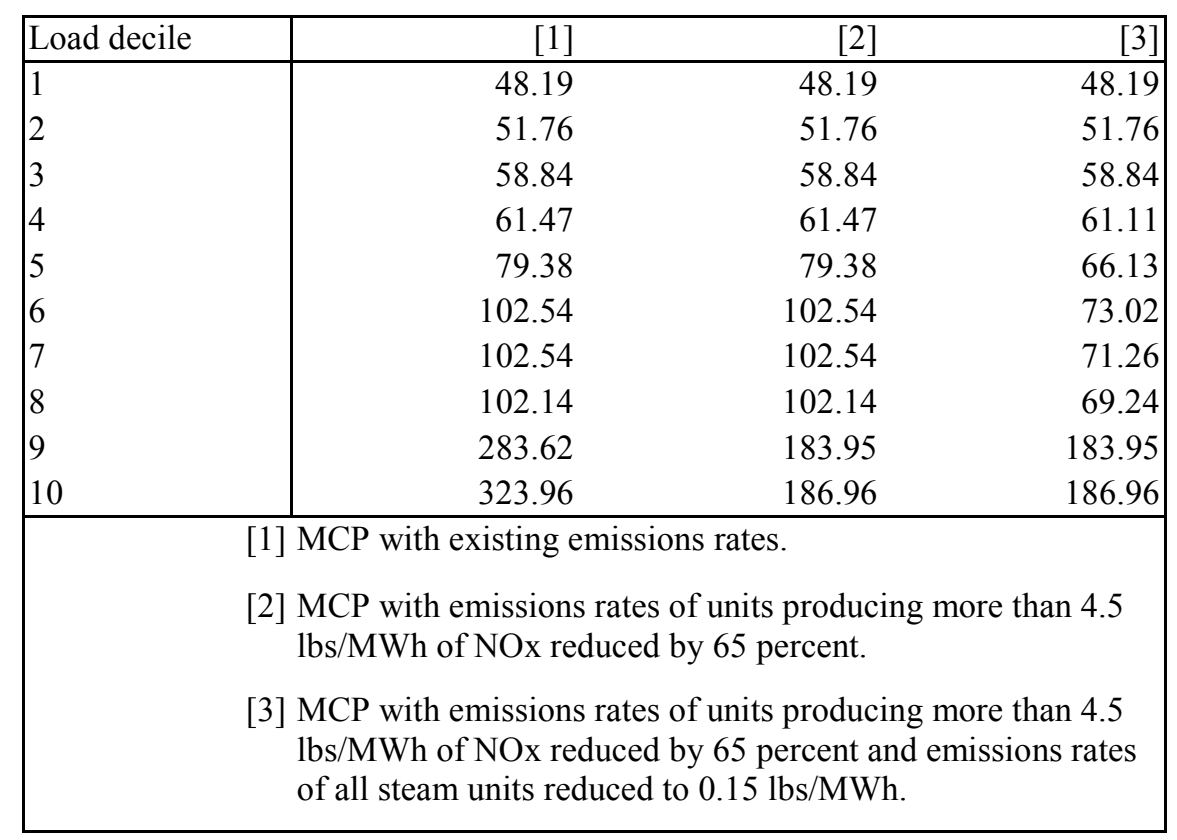

Note, as well, that our calculations only take account of the fact that NOx controls reduce the number of NOx RTCs required to supply a MWh of electricity from these units, holding NOx RTC prices constant. However, a program of accelerating NOx controls would also lead to a reduction in the demand for NOx RTCs. This in turn would lead both to lower NOx RTC prices and, as a consequence, to lower wholesale electricity prices. Thus, the implementation of NOx controls would have a second indirect impact on wholesale electricity prices by reducing the price of NOx RTCs.

It is clear that initiatives aimed at significantly reducing NOx emissions in the SCAQMD could lead to much lower competitive wholesale electricity prices. Accordingly, policies aimed at accelerating the implementation of cost-effective NOx control strategies in the SCAQMD should be given the highest priority by policymakers in California.

\footnotetext{
${ }^{24}$ Using an average hourly ISO load of 30,000 MW for 24 hours per day and 123 days in the period.
} 
Table 5. Summer Average MCP With Different NOx Controls

\begin{tabular}{|c|c|c|c|}
\hline & [1] & [2] & [3] \\
\hline \multicolumn{4}{|c|}{ NOx at $\$ 10 / 1 b$} \\
\hline June & 62.60 & 58.92 & 57.72 \\
\hline July & 61.49 & 57.84 & 55.97 \\
\hline August & 87.01 & 79.90 & 76.31 \\
\hline September & 83.41 & 79.74 & 76.41 \\
\hline \multicolumn{4}{|c|}{ NOx at $\$ 20 / 1 b$} \\
\hline June & 70.12 & 62.77 & 60.12 \\
\hline July & 67.98 & 60.67 & $\mathbf{5 8 . 7 2}$ \\
\hline August & 102.49 & 88.27 & 80.62 \\
\hline September & 91.59 & 84.25 & 78.98 \\
\hline \multicolumn{4}{|c|}{ NOx at $\$ 35 / 1 b$} \\
\hline June & 81.85 & 67.90 & 63.91 \\
\hline July & 79.09 & 65.21 & 62.77 \\
\hline August & 121.50 & 97.82 & 87.09 \\
\hline September & 104.36 & 90.99 & 83.04 \\
\hline \multicolumn{4}{|c|}{ [1] MCP with existing emissions rates. } \\
\hline \multicolumn{4}{|c|}{$\begin{array}{l}\text { [2] MCP with emissions rates of units producing more } \\
\text { than } 4.5 \mathrm{lbs} / \mathrm{MWh} \text { of NOx reduced by } 65 \text { percent. }\end{array}$} \\
\hline & \multicolumn{3}{|c|}{$\begin{array}{l}\text { [3] MCP with emissions rates of units producing more } \\
\text { than } 4.5 \mathrm{lbs} / \mathrm{MWh} \text { of NOx reduced by } 65 \text { percent and } \\
\text { emissions rates of all steam units reduced to } 0.15 \\
\text { lbs/MWh. }\end{array}$} \\
\hline
\end{tabular}

\section{Physical Withholding: The Economic Logic}

The previous analyses shows that "market fundamentals" cannot fully account for the high levels of observed prices in the Summer of 2000. Even after accounting for lower levels of imports and very high NOx RTC prices, we still observe a large deviation of wholesale market prices from the competitive benchmark price, i.e., marginal costs of supplying additional electricity at the associated market clearing quantities. However, while we observe large price/marginal cost margins during the Summer of 2000 which are inconsistent with competitive markets, our analysis so far does not measure behavior that is likely to be the cause of these high prices. In the next two sections we investigate the hypothesis that withholding behavior by generators in California is one cause of high prices. It is clear from first principles that supply withholding could be the source of high prices. Whether this is, in fact, the case is an empirical question. McCullough (2000) strongly suggests that output levels from California generators were less than was economic during the summer of 2000.

We begin by outlining simply the profit maximization logic behind capacity withdrawal and show that rational capacity withholding does not require collusion among 
suppliers. We consider the unilateral case, i.e. only one portfolio player adopts this strategy and all other generators behave competitively and bid in their supplies into the market at prices equal to their marginal cost. We can characterize the profit effects of capacity withdrawal simply as the sum of two effects. These are (1) the increased profits on the capacity offered after withdrawal due to the ability to raise price, (2) the lost profits of capacity withdrawn (see Wolfram, 1998). The profit changes must-take account of the cost reduction due to not producing on the withdrawn capacity. We can express these effects as follows:

\section{$\Delta$ Profit $=\Delta$ Price* Remaining Quantity $-\Delta$ Capacity $*$ Competitive Price $+\Delta$ Operating Cost.}

This expression is derived formally in the Appendix.

As is apparent from the formula, whether withdrawing capacity is in the self interest of a portfolio generator will depend critically upon the slope of the supply curve during the period of withholding. It must be steep enough to result in MCPs sufficiently high so that the increase in profit on generation still tendered to the market more than offsets the profits lost on the capacity withdrawn. We construct some examples based on our benchmark estimate of the supply conditions that prevailed in June 2000. These estimates come from our June simulations (without NOx effects). We examine one case, at high loads, where a load increase or capacity withdrawal of $1000 \mathrm{MW}$ results in a price increase of about $\$ 10$ per MWh. Our second case, at lower loads, produces only a $\$ 1$ price increase for the same $1000 \mathrm{MW}$ withdrawal.

Table 6 displays the profitability effects of capacity withholding for the two examples. In both cases, we make three assumptions: 1) the portfolio generator with $3,000 \mathrm{MW}$ of capacity produces only half that amount; 2) the competitive MCP is $\$ 60 / \mathrm{MWh} ; 3)$ the generator's marginal cost is $\$ 55 / \mathrm{MWh}$. In the first case, where capacity withdrawal raises price significantly, the revenue gain is large. In the second case, the impact of withholding capacity on price is relatively small because supply is much more elastic over the relevant range of output. The revenue effect of withholding is a net loss, since the increase in price on the tendered generation does not offset the lost profits on generation withheld. The details of these results are shown in the following table.

Table 6. Unilateral Market Power Examples

\begin{tabular}{|r|r|r|r|r|}
\hline Case & Revenue loss & Revenue gain & Cost savings & $\Delta$ Profit \\
\hline $\begin{array}{r}\Delta \text { Case 1, High } \\
\text { Price Increase }\end{array}$ & 90,000 & $25,714.29$ & 78,750 & $14,464.29$ \\
\hline $\begin{array}{r}\Delta \text { Case 2, Low } \\
\text { Price Increase }\end{array}$ & 90,000 & $2,571.43$ & 82,500 & $-4,928.57$ \\
\hline
\end{tabular}

These examples rely on the assumption that only one supplier withholds capacity, while all of the other suppliers behave competitively. In the California electricity market during the Summer of 2000, it appears that more than one portfolio player was implementing a withholding strategy. We illustrate this claim empirically in the next 
section. If multiple suppliers are behaving strategically, the effects of withholding on wholesale market prices could be larger.

\section{Empirical Analysis of Withholding}

Now we turn to the analysis of physical supply and withholding behavior. We use plant and unit level output data from EPA and the WSCC to examine the physical behavior of the price setting firms to determine whether there is really "scarcity" or whether it appears that the generators are withholding supplies from the market when it would be profitable for a generator without market power to supply more.

We restrict our analysis to a set of high priced hours when it should have been economical for virtually all of the fossil generators to have found it economical to supply in a competitive market. These are all hours for which the PX Day Ahead Unconstrained Price exceeded \$120/MWh in June, \$90/MWh in July, \$130/MWh in August and $\$ 110 / \mathrm{MWh}$ in September. We compare observed levels of production by unit generators likely to be setting prices, with their maximum generating capacities during those hours. NP 15 generation is analyzed separately from SP 15. There is a substantial "output gap" between observed and maximum levels of generation in both zones. Three factors may explain this gap: (1) capacity may be covering the CAISO's ancillary services requirements, (2) capacity may be out of service due to forced outages, and (3) interzonal transmission constraints (South to North) may limit economic dispatch of SP 15 plants. Therefore, we test whether the gap can be explained by these three factors. If the gap cannot be explained, we conclude that it is indicative of generator withholding resulting either from high bids that do not clear the day-ahead or real time energy markets or direct withholding of capacity from these markets.

- The tests of the output gap for ancillary services requirements have two elements: (1) We compare the zonal CAISO ancillary services requirement in the selected hours against the output gap and (2) We consider whether the CAISO dispatched replacement reserves during our sample hours. If reserves were dispatched, they will appear as production in our data and would, therefore, not explain any output gap.

- The test of the output gap for forced outages is necessarily limited in its applicability. As explained in detail below, we rely on two data sources: EPA and WSCC. The EPA data are sufficiently disaggregated to support an analysis of forced outages, whereas the WSCC data are not. We apply three outage tests to the EPA data to ascertain whether forced outages might explain output gaps.

- The test of the output gap for the effects of interzonal transmission constraints requires that we review congestion during our sample hours, between the CAISO zones that might limit economic dispatch of plants. Production levels in hours without a constraint should not be affected by transmission issues. 
We rely on two data sources for this analysis; both have hourly production data, but the sources differ by the level of aggregation. The first source gives unit-specific data. These data are available from the Environmental Protection Agency's (EPA) Continuous Emissions Monitoring System (CEMS). The CEMS database tracks hourly production and emissions of certain pollutants that are regulated under the Clean Air Act. CEMS data for the second quarter of 2000 are available on the EPA's website. ${ }^{25}$ CEMS data do not include gas turbines and some small thermal units. Table 7 below lists the units in SCAQMD that are omitted from the CEMS database, their ownership, capacity and NOx emission rates. The second source gives data at the plant level, not the unit level. These data are from the WSCC's Extra High Voltage (EHV) database. The EHV data, which are available to all WSCC members, were provided to us by SCE. These data exclude plants of less than $250 \mathrm{MW}^{26}$

Table 7. Units Excluded from CEMS Database

\begin{tabular}{|llcc|}
\hline Unit & Owner & June Capacity $(\mathrm{MW})$ & NOx $(\mathrm{lbs} / \mathrm{MWh})$ \\
\hline Long Beach 8 & Dynegy & 265 & 1.2 \\
Long Beach 9 & Dynegy & 265 & 1.2 \\
Highgrove 1-4 $(*)$ & Thermo Ecotek & 154 & $1.2-2.4$ \\
Etiwanda GT & Reliant & 126 & 5.4 \\
Alamitos GT & AES & 133 & 6.5 \\
Huntington Beach GT & AES & 133 & 5.7 \\
Elwood GT & Reliant & 48 & 5.4 \\
Mandalay GT & Reliant & 140 & 5.7 \\
\hline (*) While Highgrove reports emissions data as part of the EPA program, these & \\
plants didn't operate in the relevant time period. & \\
Capacity figures are from Henwood. & \\
NOx are calculated from publicly available data. & \\
\hline
\end{tabular}

The overlap between these two data sources is incomplete; the EPA data are more disaggregated, but exclude small steam units and gas turbines. To determine the extent of the comparability between the data sets, we compared hourly generation reported by both sources for June for five plants: El Segundo, Pittsburg, Moss Landing, Morro Bay, and Ormond Beach. None of these plants have units that are excluded from the EPA dataset. Thus, hourly production reported should be comparable between the two sources. We found that the correlation between the hourly production data was about 95 percent for each plant and that the mean hourly output over the month differed by about 5 percent. On this basis we concluded that we could use both data sources to develop a reasonably complete picture of physical behavior during the June-September period. We begin our discussion with an analysis of June based on the EPA data. We will address data comparability further when we turn to the analysis that uses the EHV data.

\footnotetext{
${ }^{25}$ CEMS data for the third quarter of 2000 will not become available until after 1/1/2001.

${ }^{26}$ For example, the Potrero plant in San Francisco is included in the EPA data but not in the EHV data.
} 


\section{EPA CEMS Analysis of June}

Within June, we confine our attention to hours when the unconstrained PX price was at $\$ 120 / \mathrm{MWh}$ or more. There were 137 such hours in June. Our analysis attempts to discover if there is an unexplained gap between maximum production by generators and observed production during the so-called scarcity periods. An otherwise unexplained gap would tend to support our hypothesis that production was withheld by generators in an attempt to drive up price during these periods.

First, we compute the aggregate output gap for all generators in the EPA database for June hours when the Unconstrained PX price is above $\$ 120 / \mathrm{MWh}$; there are 137 hours that meet this criterion. In each of the 137 hours when the price is above \$120/MWh, we observe the hourly output of generators owned by Duke, Southern, AES, Dynegy and Reliant. At $\$ 120 / \mathrm{MWh}$, the price is above the marginal costs of all generators in the EPA database, ${ }^{27}$ thus, we expect to find that production in these hours will be at maximum levels. Next, we sum up the hourly output for each firm in NP15 and in SP15 separately. We compare the June production of each generator over each of the 137 hours to their observed aggregate maximum output in the second quarter of 2000 . We define the output gap for each firm to be the difference between that maximum output and the observed output in each of the 137 high priced hours. It is important to note that the dispatch of these generators may be controlled by contractual arrangements with third parties other than the owners of the generating plants. We do not know for a fact to what extent this is the case. We use the owners simply to identify the generating plants examined and any apparent withholding observed.

Next, we want to see how much of the gap can be explained by the CAISO's reservation of capacity for Ancillary Services (we include Up Regulation, Spin, Non-Spin and Replacement Reserves). ${ }^{28}$ Public data on CAISO demands for Ancillary Services (AS) are available by zone. We compare the output gap by zone to AS capacity by zone for each hour. The AS demand includes both the Day Ahead and the Hour Ahead demands. Table 8 below summarizes our results.

\footnotetext{
27 The June gas prices were under \$5/MMBtu. The marginal heat rates for these generators are less than $12,000 \mathrm{Btu} / \mathrm{kWh}$. This means that marginal fuel cost is $<\$ 60 / \mathrm{MWh}$. For those units in SCAQMD, their NOx emission rates are all $<2 \mathrm{lbs} / \mathrm{MWh}$. Therefore at $\$ 10 / \mathrm{lb}$ RTC costs, these units have marginal costs of $<\$ 80 / \mathrm{MWh}$.

${ }^{28}$ We exclude Down Regulation, because that does not require that capacity be held in reserve.
} 
Table 8. Mean Level of the Output Gap for High-Price Hours (June 2000, EPA data)

\begin{tabular}{|c|c|c|c|c|c|}
\hline Zone & Owner & $\begin{array}{r}\text { Mean output } \\
(\mathrm{MWh})\end{array}$ & $\begin{array}{r}\text { Max output } \\
(\mathrm{MWh})\end{array}$ & $\begin{array}{r}\text { Mean output } \\
\text { gap (MWh) }\end{array}$ & $\begin{array}{r}\text { Mean AS } \\
\text { Demand } \\
(\mathrm{MWh})\end{array}$ \\
\hline \multicolumn{6}{|c|}{ All hours } \\
\hline \multirow[t]{3}{*}{ NP15 } & Duke & 2422 & 2563 & 141 & \\
\hline & Southern & 2090 & 2932 & 842 & \\
\hline & Total & & & 983 & 1510 \\
\hline \multirow[t]{5}{*}{ SP15 } & AES & 2542 & 3681 & 1139 & \\
\hline & Duke & 643 & 733 & 90 & \\
\hline & Dynegy & 1014 & 2000 & 986 & \\
\hline & Reliant & 2351 & 3487 & 1136 & \\
\hline & Total & & & 3351 & 1672 \\
\hline
\end{tabular}

For SP15, the mean of the output gap is $3351 \mathrm{MW}$ compared to $1672 \mathrm{MW}$ for the mean of the AS demands in the zone. This leaves an average unexplained output gap of 1679 MW during the 137 hours, assuming that all of AS capacity requirements were covered by these plants. Based on these results, it looks as if capacity is being withdrawn on average during this period in SP15. The results for NP15 are different. Here the mean of the output gap is $983 \mathrm{MW}$, which is less than the mean demand for AS services, 1510 MW. Therefore, we cannot conclude definitely that there was capacity withholding in NP15. It is important to point out, however, that this assessment is quite crude and supplies an upper bound on AS capacity requirements that might explain the output gap. This is due to three factors: (1) it neglects the possibility that hydro capacity or imports are supplying some of the AS demand; (2) ramp rate restrictions might have made it physically impossible for the plants to supply the AS full requirement; (3) replacement reserve was frequently dispatched by the CAISO during the summer, dispatched reserves would have been reflected as production in these data. While we attempt to account for the effects of dispatching reserves on our analysis, we are unable to test the effects of alternative suppliers of AS services or those of ramp rate restrictions because of data limitations. If we had access to confidential data available to the CAISO, we could also determine if these additional factors would affect our results.

An alternative way of expressing these results is to identify the size of the hourly output gaps (net of AS procured in the zone) together with the number of hours in which the gap occurs. We have computed this distribution both with and without accounting for the effect of dispatched reserves on the net output gap. Table 9 below displays these 
calculations, starting at a level of $500 \mathrm{MW}$ of withheld capacity net of AS demands. For example, there were 88 hours in June when net capacity of more than $1000 \mathrm{MW}$ appear to have been withheld in SP15 before accounting for dispatched reserves. After including the potential effects of dispatched reserves in our analysis of AS capacity requirements, there were 126 hours in June when net capacity of more than $1000 \mathrm{MW}$ appear to have been withheld.

Thus far our calculations make no attempt to assess whether the output gap can be explained by unscheduled outages. We examine this question next. Evaluating the effects of unscheduled (forced) outages is not completely straight-forward, because of the discretionary element in outages. Therefore we apply three different tests for forced outages. Test 1 measures the maximum output for a generation portfolio by looking only at units that were producing any output in the hour in question. This is the strictest definition of a "no outage condition." Test 2 measures the maximum output for a generation portfolio by looking only at units that were producing any output in the day in question. Finally Test 3 measures the maximum output for a generation portfolio by looking only at units that were producing any output in the day in question or the day before. Another way of describing Test 3 is that an outage is real only if it occurred both the day before the day of our scarcity hours as well as the day of such an event.

Table 9. Hourly Distribution of the Output Gap Net of Zonal AS (June 2000, EPA data)

\begin{tabular}{|c|c|c|c|c|}
\hline & \multicolumn{2}{|c|}{ All hours } & \multicolumn{2}{|c|}{$\begin{array}{l}\text { Hours without south to } \\
\text { north congestion }\end{array}$} \\
\hline & NP15 & SP15 & NP15 & SP15 \\
\hline \multicolumn{5}{|c|}{ All AS } \\
\hline$>500 \mathrm{MWh}$ & 15 & 96 & 13 & 88 \\
\hline$>1000 \mathrm{MWh}$ & 5 & 88 & 5 & 80 \\
\hline$>2000 \mathrm{MWh}$ & 0 & 60 & 0 & 53 \\
\hline$>3000 \mathrm{MWh}$ & 0 & 22 & 0 & 19 \\
\hline$>4000 \mathrm{MWh}$ & 0 & 10 & 0 & 8 \\
\hline \multicolumn{5}{|c|}{ AS net of replacement } \\
\hline$>500 \mathrm{MWh}$ & 23 & 136 & 21 & 124 \\
\hline$>1000 \mathrm{MWh}$ & 11 & 126 & 11 & 115 \\
\hline$>2000 \mathrm{MWh}$ & 0 & 74 & 0 & 67 \\
\hline$>3000 \mathrm{MWh}$ & 0 & 25 & 0 & 21 \\
\hline$>4000 \mathrm{MWh}$ & 0 & 10 & 0 & 8 \\
\hline Total high price hours & 137 & 137 & 125 & 125 \\
\hline \multicolumn{5}{|c|}{ High price hours are hours for which the PX price exceeded $\$ 120 / \mathrm{MWh}$. } \\
\hline
\end{tabular}


Table 10 shows that the mean gap falls compared with the results on Table 8 as expected. Qualitatively, SP15 shows a mean output gap that is between 282 and $682 \mathrm{MW}$ greater than the mean zonal AS requirement (1672) in the zone depending on the outage test used. These results change if adjusted for the average $628 \mathrm{MW}$ of replacement reserve capacity (see Table 12) that may have been dispatched during the sample hours in June. Following that adjustment, the mean output gap in SP15 after accounting for outages is between 910 and $1310 \mathrm{MW}$. 
Table 10. Maximum Potential Output and Mean Output Gap: Outage Definitions (June 2000, EPA data)

\begin{tabular}{|c|c|c|c|c|c|c|c|}
\hline \multirow[b]{2}{*}{ Zone } & \multirow[b]{2}{*}{ Owner } & \multicolumn{2}{|c|}{ Test 1} & \multicolumn{2}{|c|}{ Test 2} & \multicolumn{2}{|c|}{ Test 3} \\
\hline & & $\begin{array}{r}\text { Max output } \\
\text { (MWh) }\end{array}$ & $\begin{array}{r}\text { Mean output } \\
\text { gap (MWh) }\end{array}$ & $\begin{array}{r}\text { Max output } \\
(\mathrm{MWh})\end{array}$ & $\begin{array}{r}\text { Mean output } \\
\text { gap (MWh) }\end{array}$ & $\begin{array}{r}\text { Max output } \\
\text { (MWh) }\end{array}$ & $\begin{array}{r}\text { Mean output } \\
\text { gap (MWh) }\end{array}$ \\
\hline \multirow[t]{3}{*}{ NP15 } & Duke & 2541 & 119 & 2563 & 141 & 2563 & 141 \\
\hline & Southern & 2395 & 571 & 2765 & 675 & 2767 & 676 \\
\hline & Total & & 690 & & 816 & & 818 \\
\hline \multirow[t]{5}{*}{ SP15 } & AES & 2945 & 403 & 3120 & 577 & 3157 & 615 \\
\hline & Duke & 723 & 79 & 733 & 90 & 733 & 90 \\
\hline & Dynegy & 1611 & 597 & 1646 & 632 & 1684 & 670 \\
\hline & Reliant & 3225 & 874 & 3286 & 935 & 3330 & 979 \\
\hline & Total & & 1954 & & 2234 & & 2354 \\
\hline
\end{tabular}

High price hours are hours for which the PX price exceeded \$120/MWh.

Test 1 includes all units with positive production in a specific hour in the calculation of maximum potential output for that hour.

Test 2 includes all units with positive production in the same day in the calculation of maximum potential output for an hour.

Test 3 includes all units with positive production in the current or previous day in the calculation of maximum potential output for an hour.

For SP15, Table 11 shows the number of hours that the output gap minus the total AS demand exceeds particular levels under each of the three outage tests identified above. As can be seen from the table, there are still roughly 50 high-price hours during June 2000 when more than 1000 MW appears to have been withheld from the market before inclusion of hours during which AS reserve capacity may have been dispatched. Inclusion of these additional 38 hours (see Table 9) would leave 88 high-price hours when more than $1000 \mathrm{MW}$ appears to have been withheld from the market. 


\section{Table 11. Hourly Distribution of SP 15 Output Gap Net of Zonal AS for 3 Outage Tests (June 2000, EPA data)}

\begin{tabular}{|lrrr|}
\hline & Test1 & Test 2 & Test 3 \\
\hline & All hours & & \\
$>500 \mathrm{MWh}$ & 57 & 68 & 72 \\
$>1000 \mathrm{MWh}$ & 44 & 50 & 54 \\
$>2000 \mathrm{MWh}$ & 15 & 20 & 25 \\
$>3000 \mathrm{MWh}$ & 7 & 9 & 11 \\
$>4000 \mathrm{MWh}$ & 4 & 6 & 6 \\
\hline & & & \\
Total high price hours & 137 & 137 & 137 \\
\hline & Hours without south to north congestion \\
$>500 \mathrm{MWh}$ & 49 & 60 & 64 \\
$>1000 \mathrm{MWh}$ & 37 & 43 & 47 \\
$>2000 \mathrm{MWh}$ & 11 & 16 & 9 \\
$>3000 \mathrm{MWh}$ & 6 & 7 & 5 \\
$>4000 \mathrm{MWh}$ & 3 & 5 & 125 \\
\hline & & & \\
Total high price hours & 125 & 125 &
\end{tabular}

High price hours are hours for which the PX price exceeded \$120/MWh.

Real-time south to north congestion exists when the real-time price north of Path 15 exceeds the real-time price south of Path 15.

Zonal ancillary services include up-regulation, replacement reserves, spinning reserves, and non-spinning reserves.

Test 1 includes all units with positive production in a specific hour in the calculation of maximum potential output for that hour.

Test 2 includes all units with positive production in the same day in the calculation of maximum potential output for an hour.

Test 3 includes all units with positive production in the current or previous day in the calculation of maximum potential output for an hour.

Logically, congestion on the transmission system could help to explain the output gaps we have identified. While intrazonal constraints would not affect production levels within a zone, interzonal constraints potentially could. We therefore have examined data on interzonal transmission levels and congestion to determine if transmission congestion has had the affect of contributing to the output gaps. Since it appears that withholding was most likely in the SP15 zone, we have reviewed the possible impacts of South to North congestion on our findings. Tables 9 and 11 include hourly distribution of the output gaps, after eliminating hours for which this transmission path is constrained. We found that while interzonal transmission constraints do occur occasionally, in June they are limited to less than 10 percent of the scarcity hours. Thus, the effects of constraints on the production levels and output gaps analyzed here are minor. 


\section{EHV Data Analysis}

First we use the same approach to analyze the June EHV data that we applied to the EPA data above, and then we compare our analysis using the June EHV data with the previous discussion. Table 12 parallels Table 8 above. The main difference between these tables is that the EHV data includes about $1300 \mathrm{MW}$ of capacity in SP15 that is excluded from the EPA data. ${ }^{29}$ However, the mean output in SP15 using the EHV data only increases by about $350 \mathrm{MW}$, so the mean output gap increases by about $1000 \mathrm{MW}$ in this zone. The results for NP15 are about 115 MW less than are shown on Table 8.

\section{Table 12. Mean Level of the Output Gap} (June 2000, EHV data)

\begin{tabular}{|c|c|c|c|c|c|}
\hline Zone & Owner & $\begin{array}{r}\text { Mean output } \\
\text { (MWh) }\end{array}$ & $\begin{array}{r}\text { Max output } \\
\text { (MWh) }\end{array}$ & $\begin{array}{l}\text { Mean output } \\
\text { gap (MWh) }\end{array}$ & $\begin{array}{r}\text { AS total } \\
(\mathrm{MWh})\end{array}$ \\
\hline \multicolumn{6}{|c|}{ All hours } \\
\hline \multirow[t]{3}{*}{ NP15 } & Duke & 2354 & 2491 & 137 & \\
\hline & Southern & 1846 & 2576 & 730 & \\
\hline & Total & & & 868 & 1510 \\
\hline \multirow[t]{5}{*}{ SP15 } & AES & 2687 & 4111 & 1424 & \\
\hline & Duke & 612 & 949 & 337 & \\
\hline & Dynegy & 1239 & 2489 & 1250 & \\
\hline & Reliant & 2359 & 3678 & 1319 & \\
\hline & Total & & & 4330 & 1672 \\
\hline
\end{tabular}

Next, we extend our analysis from June, to cover the remainder of the summer. We summarize, in a more aggregated fashion, the mean output gaps as estimated in Table 12 for SP15 in June, July, August and September and include the estimated effects of dispatched reserves and of transmission congestion on the output gaps. Table 13 presents these data for each of the months June through September. For each month, we first show the SP15 mean output gap (net of AS requirements with and without replacement reserves) over all hours and then over hours for which interzonal transmission lines are unconstrained. In June and July, less than ten percent of high priced hours occur during periods of transmission congestion, and the average output gap remains relatively stable. However, in August and September almost a third of high-priced hours occur at the same time as South to North interzonal line constraints and the mean output gaps for these

\footnotetext{
${ }^{29}$ The additional capacity, which is excluded from the EPA data, includes Long Beach, small steam units, and gas turbines (see Table 6 above).
} 
months in the uncongested hours are somewhat lower that the mean taken over all highpriced hours.

Table 13. Output Gap in SP15 (June-September 2000, EHV data)

\begin{tabular}{|c|c|c|c|c|c|c|}
\hline Month & $\begin{array}{r}\text { Mean output } \\
\text { gap }\end{array}$ & Mean AS & $\begin{array}{l}\text { Mean AS net } \\
\text { of replacement }\end{array}$ & $\begin{array}{l}\text { Mean output } \\
\text { gap net of AS }\end{array}$ & $\begin{array}{r}\text { Mean output gap } \\
\text { net of non- } \\
\text { replacement AS }\end{array}$ & \# of hours \\
\hline & {$[1]$} & [2] & [3] & {$[1]-[2]$} & {$[1]-[3]$} & \\
\hline & \multicolumn{5}{|c|}{ All hours } & \\
\hline June & 4330 & 1672 & 1044 & 2658 & 3286 & 137 \\
\hline July & 3652 & 1002 & 794 & 2650 & 2858 & 194 \\
\hline August & 3322 & 1318 & 970 & 2004 & 2352 & 411 \\
\hline \multirow[t]{2}{*}{ September } & 3798 & 883 & 724 & 2914 & 3073 & 233 \\
\hline & \multicolumn{5}{|c|}{ Hours without south to north congestion } & \\
\hline June & 4300 & 1679 & 1046 & 2621 & 3253 & 125 \\
\hline July & 3623 & 1018 & 799 & 2604 & 2824 & 175 \\
\hline August & 3028 & 1429 & 1021 & 1599 & 2007 & 297 \\
\hline September & 3349 & 941 & 750 & 2408 & 2599 & 159 \\
\hline \multicolumn{7}{|c|}{$\begin{array}{l}\text { High price hours are hours for which the PX price exceeded \$120/MWh in June, } \$ 90 / \mathrm{MWh} \text { in July, } \\
\$ 130 / \mathrm{MWh} \text { in August, and } \$ 110 / \mathrm{MWh} \text { in September. (See Sheffrin }(2000) \text { ) }\end{array}$} \\
\hline
\end{tabular}

The data in Table 13 from the WSCC database are unadjusted for the effect of price caps on the economics of plants in SCAQMD with high NOx emission rates. The five gas turbines with emission rates greater than $4.5 \mathrm{lbs} / \mathrm{MWh}$ would have RTC costs greater than $\$ 157 / \mathrm{MWh}$ in August and September when RTC prices were at $\$ 35 / \mathrm{lb}$. The fuel costs of the gas turbines would be at or above $\$ 100 / \mathrm{MWh}$ during this period as well. When the price cap was lowered to $\$ 250 / \mathrm{MWh}$ on August 7 , these units had marginal costs above the cap. Therefore their capacity, about $600 \mathrm{MW}$ total, should be excluded from the output gap estimates in Table 13. There may also be a related issue for units with NOx emission rates that are in the $2 \mathrm{lb} / \mathrm{MWh}$ range. At $\$ 35 / \mathrm{lb}$, these units would have $\$ 70 / \mathrm{MWh}$ marginal costs for RTC credits at the gas prices prevailing in August and September. Some of these units might have marginal costs above the cut-off level for the scarcity hours that we examine in the aggregate here. We have not tested precisely the extent to which cost considerations could account for the output gap in August and September. These issues do not arise in June and July when RTC prices were lower.

The outage tests that we developed with the EPA data cannot be applied to the EHV results. Outages are events that occur to units, whereas the EHV data reports production only at the more aggregated station level. However, our results without consideration of outages reveal SP 15 net unexplained output gaps that are sufficiently 
large to suggest that power supplies were withheld in the zone during the June through September period.

We recognize that this analysis of capacity withholding is very rough and necessarily plagued by data imperfections. Moreover, the analysis does not examine behavior of generators outside of California, and does not account for aggregation and contractual arrangements by and with wholesale marketers. A more complete analysis is not possible without access to confidential supplier data.

\section{Conclusions}

It is clear that increases in gas prices, increased demand, reduced availability of power imports, and higher prices for emissions permits contributed to significantly higher wholesale market prices in California during 2000, compared to the previous two years. However, based on our analysis of available data, we conclude that wholesale electricity prices in California far exceeded competitive levels during the June, July and August of 2000. The high wholesale electricity prices observed in Summer 2000 cannot be fully explained as the natural outcome of "market fundamentals" in competitive markets since there is a very significant gap between actual market prices and competitive benchmark prices that take account of these market fundamentals. Moreover, there is considerable empirical evidence to support a presumption that the high prices experienced in the summer of 2000 reflect the withholding of supplies from the market by suppliers (generators or marketers). We base these conclusions on results of the two analyses described herein:

- Competitive Benchmark Price Analysis: Observed prices in California in Summer 2000 were greater than benchmark competitive price levels; these differences are not fully explained by higher loads, reduced levels of imports, high gas prices or by high prices for NOx RTCs.

- Capacity Withholding Analysis: The information that we have available to us suggests that withholding of capacity in SP 15 to drive up price occurred during Summer 2000. We find a substantial gap between maximum levels of generation and observed levels in those hours identified as scarcity hours by others. This gap cannot be explained by the CAISO's requirements for ancillary services or by reasonable estimates of forced outages. While our analysis of withholding is necessarily limited by the data available to us, there is sufficient empirical evidence to suggest that the high observed prices reflect suppliers exercising market power. 


\section{References}

Borenstein, S., J. Bushnell and F. Wolak, "Diagnosing Market Power in California"s deregulated Wholesale Electricity Market," University of California Energy Institute working paper PWP-064, August, 2000. Available at

http://www.path.berkeley.edu/ucei/PDFDown.html

Borenstein, S., J. Bushnell, C. Knittel, and C. Wolfram, "Price Convergence in California's Deregulated Wholesale Electricity Market," Proceedings of the University of California Energy Institute Conference, March, 2000.

California Energy Commission, (CEC) "Market Clearing Prices Under Alternative Resource Scenarios, 2000-2010,” Staff Report, March 2000.

California Independent System Operator Department of Market Analysis, California Energy Market Issues and Performance: May-June, 2000, August 10, 2000.

California Power Exchange Corporation Compliance Unit, (CaPX) Price Movements in California Electricity Markets: Analysis of Price Activity May-July 2000, September 29, 2000.

Carlton, Dennis W. and Jeffrey M. Perloff, Modern Industrial Organization, Third Edition, Addison Wesley Longman, 1999.

Ellerman, D., P. Joskow, R. Schmalensee, J. Montero and E. Bailey. Markets for Clean Air: The U.S. Acid Rain Program. Cambridge University Press, 2000.

Federal Energy Regulatory Commission, (FERC) Staff Report to the Federal Energy Regulatory Commission on the Causes of Wholesale Electricity Pricing Abnormalities in the Midwest During June 1998, September 22, 1998.

Federal Energy Regulatory Commission, (FERC Staff Report) Staff Report to the Federal Energy Regulatory Commission on Western Markets and the Causes of the Summer 2000 Price Abnormalities, November 1, 2000.

Henwood Energy Services Incorporated (HESI), Database for the Western Systems Coordinating Council, 2000.

Hildebrandt, E., Declaration of Eric Hildebrandt, Federal Energy Regulatory Commission Docket No. EL00-95-000 and Docket No. EL00-98-000, October, 2000.

Joskow, Paul L. "Regulatory Failure, Regulatory Reform and Structural Change In The Electric Power Industry", Brookings Papers on Economic Activity: Microeconomics. 1989. 
Joskow, Paul L., "Deregulation and Regulatory Reform in the U.S. Electric Power Sector," in Deregulation of Network Industries: The Next Steps (S. Peltzman and Clifford Winston, eds.), Brookings Press, 2000.

Kahn, M. and L. Lynch, California's Electricity Options and Challenges: Report to Governor Gray Davis, August 2, 2000

Klein, J. The Use of Heat Rates in Production Cost Modeling and Market Modeling, 1998, http://www.energy.ca.gov/papers/98-04-07_HEATRATE.PDF

McCullough, R., "Tsunami: Western Power Market Prices Since May 22, 2000," presentation at Energy Market Report Conference, Portland, OR, October 12, 2000.

Overduin, C., "Test Report Water Injection and Opacity Tests at Alamitos Generating Station Unit 7, Southern California Edison Company Power Systems Engineering and Construction, 1994.

Sheffrin, A., "Options for System Market Power Mitigation," presentation to ISO Board Meeting, October 4, 2000.

Tirole, Jean, The Theory of Industrial Organization, MIT Press, 1988.

U.S. Department of Energy (DOE), Report of the U.S. Department of Energy's Power Outage Study Team, March, 2000.

U.S. Environmental Protection Agency (EPA), Analyzing Electric Power Generation under the CAAA, Appendix 5: Pollution Control Performance and Costs, March, 1998.

Wolfram, C. "Measuring Duopoly Power in the British Electricity Spot Market," American Economic Review, 89(4), 805-826, 1999.

Wolfram, C., "Strategic Bidding in a Multi-Unit Auction: An Empirical Analysis of Bids to Supply Electricity in England and Wales," RAND Journal of Economics, 29(4), 703$725,1998$.

Wolak, F., R. Nordhaus and C. Shapiro, An Analysis of the June 2000 Price Spikes in the California ISO’s Energy and Ancillary Services Markets, September, 2000. 


\section{Appendices}

These Appendices present data underlying our analysis and/or illustrating our methods.

\section{A. Comparison with BBW}

\begin{tabular}{|c|c|c|c|c|c|c|}
\hline \multicolumn{2}{|l|}{ Month } & \multicolumn{3}{|c|}{ Average MC (\$/MWh) } & \multicolumn{2}{|c|}{ Market heat rate (MBtu/MWh) } \\
\hline & & BBW & JK & & BBW & JK \\
\hline & & [1] & [2] & $([2]-[1]) /[1]$ & {$[3]$} & [4] \\
\hline \multirow[t]{9}{*}{1999} & Jan & 22.71 & 23.60 & $3.9 \%$ & 9,678 & 10,055 \\
\hline & Feb & 21.26 & 22.43 & $5.5 \%$ & 9,438 & 9,957 \\
\hline & Mar & 20.88 & 21.78 & $4.3 \%$ & 9,652 & 10,068 \\
\hline & Apr & 24.17 & 25.00 & $3.4 \%$ & 9,549 & 9,876 \\
\hline & May & 25.30 & 25.74 & $1.7 \%$ & 9,509 & 9,675 \\
\hline & Jun & 25.70 & 25.16 & $-2.1 \%$ & 9,380 & 9,183 \\
\hline & Jul & 27.30 & 26.35 & $-3.5 \%$ & 9,825 & 9,483 \\
\hline & Aug & 32.00 & 30.20 & $-5.6 \%$ & 10,090 & 9,522 \\
\hline & Sep & 30.71 & 29.55 & $-3.8 \%$ & 9,918 & 9,543 \\
\hline [3] & $1000 *[1] / \mathrm{Mc}$ & averas & $\overline{\text { E burn }}$ & ip price & & \\
\hline \multirow[t]{2}{*}{ [4] } & $1000 *[2] / \mathrm{Mc}$ & averą & E burn & ip price & & \\
\hline & Publicly avai & data or & time $n$ & nports begi & January 1999 & \\
\hline
\end{tabular}

We believe that the largest contributor to the differences between our monthly estimates and those of BBW have to do with scheduled and unscheduled outages. As noted previously, BBW have available the hourly level of production by must-take resources. This includes the effect of both kinds of outages. We have relied on ex ante estimates and a maintenance scheduling heuristic, which is likely to be imprecise.

\section{B. Net Import Adjustment}

The following table shows actual PX prices, estimated marginal costs using our methods, actual net imports, and estimated competitive net imports for each load decile in July 2000. Our estimates of competitive net imports are uniformly below observed net imports because our estimates of marginal costs are uniformly below observed PX prices.

\begin{tabular}{|r|rrrr|}
\hline \multicolumn{5}{|c|}{ Sample net import calculation for July 2000 } \\
\hline Load decile & PX price & MC & Actual NI & Estimated NI \\
& {$[1]$} & {$[2]$} & {$[3]$} & {$[4]$} \\
\hline 1 & 39.50 & 40.25 & 4575 & 4604 \\
2 & 46.64 & 43.20 & 4438 & 4326 \\
3 & 53.51 & 45.48 & 4533 & 4294 \\
4 & 55.53 & 48.78 & 4121 & 3947 \\
5 & 62.23 & 49.42 & 3963 & 3670 \\
6 & 69.05 & 49.42 & 3968 & 3549 \\
7 & 81.00 & 49.27 & 4239 & 3592 \\
8 & 114.02 & 50.25 & 4476 & 3406 \\
9 & 187.78 & 54.44 & 4385 & 2902 \\
10 & 349.46 & 103.52 & 3802 & 2534 \\
\hline \multicolumn{5}{c}{} \\
\hline
\end{tabular}




\section{Hydro Dispatch Example}

\begin{tabular}{|rr|}
\hline \multicolumn{2}{|c|}{ Average decile hydro energy (July 2000) } \\
\hline Load decile & Average hourly hydro energy \\
& (MWh) \\
\hline 1 & 3155 \\
2 & 3155 \\
3 & 3155 \\
4 & 3155 \\
5 & 3155 \\
6 & 4785 \\
7 & 8000 \\
8 & 8000 \\
9 & 8000 \\
10 & 8000 \\
\hline
\end{tabular}

\section{Unilateral Market Power}

This exercise explores the profitability of a generator withholding capacity relative to a competitive baseline in which price is set by industry marginal cost and all generation with marginal cost below the market-clearing price is dispatched. We assume that all other generators produce at competitive levels and demand is completely inelastic. Under these assumptions, the effect of withholding on price is the same as a leftward shift of the industry supply curve by the amount of withholding.

Suppose that all of a generator's capacity $q_{c}$ is economic at a hypothetical competitive market-clearing price $p_{c}$. If it bid all of the capacity at below the market-clearing price, it would earn profits

$\Pi^{c}=p_{c} q_{c}-c\left(q_{c}\right)$

where $c\left(q_{c}\right)$ represents its total cost of producing $q_{c}$.

Now, suppose that the same generator can raise the market-clearing price by withholding and producing $q_{l}<q_{c}$. In this case, its profits would be

$\Pi^{l}=p_{l} q_{l}-c\left(q_{l}\right)$

where 
$p_{l}=p_{c}+\frac{\Delta p}{\Delta q} \cdot \Delta q$

and $\Delta q$ is the extent of the generator's withholding.

The change in the generator's profits due to withholding is then

$$
\Delta \Pi=p_{c}\left(q_{l}-q_{c}\right)+\frac{\Delta p}{\Delta q} \cdot \Delta q q_{l}+\left(c\left(q_{c}\right)-c\left(q_{l}\right)\right)
$$

The first term represents the revenue loss from producing at a lower level of output, the second term represents increased per unit revenue on remaining output, and the final term represents the cost savings from producing less. The profits from withholding are the sum of these three components.

If the generator's marginal costs at $q_{c}$ and $q_{l}$ are $M C\left(q_{c}\right)$ and $\operatorname{MC}\left(q_{l}\right)$ and we assume that marginal cost is linear between $q_{c}$ and $q_{l}$, then

$$
c\left(q_{c}\right)-c\left(q_{l}\right)=\left(0.5 \cdot M C\left(q_{l}\right)+0.5 \cdot M C\left(q_{c}\right)\right) \cdot\left(q_{c}-q_{l}\right)
$$

Based on assumptions about the generator's marginal costs at different output levels and the slope of the industry supply curve, i.e. the extent to which prices rise as inframarginal capacity is withheld, we can calculate the gains from withholding a specific quantity of capacity. Table 5 shows a few numerical examples. The following table shows how to estimate the slope of the supply curve for June. Table 6 employs slopes based on a similar methodology to estimate

\begin{tabular}{|c|c|c|c|c|}
\hline \multicolumn{5}{|c|}{ Calculation of the supply curve slope (June 2000) } \\
\hline load decile & $\mathrm{MCP}$ & Load & load and reserves & $\mathrm{dp} / \mathrm{dq}_{\text {energy and reserve: }}$ \\
\hline & [1] & [2] & [3] & {$[4]$} \\
\hline 1 & 42.44 & 20793 & 22872 & \\
\hline 2 & 44.47 & 22587 & 24846 & $1.03 \mathrm{E}-03$ \\
\hline 3 & 45.80 & 24401 & 26841 & $6.68 \mathrm{E}-04$ \\
\hline 4 & 49.17 & 26763 & 29439 & $1.30 \mathrm{E}-03$ \\
\hline 5 & 49.46 & 28822 & 31704 & $1.28 \mathrm{E}-04$ \\
\hline 6 & 49.17 & 30819 & 33901 & $-1.32 \mathrm{E}-04$ \\
\hline 7 & 49.61 & 32792 & 36071 & $2.00 \mathrm{E}-04$ \\
\hline 8 & 52.23 & 34767 & 38244 & $1.21 \mathrm{E}-03$ \\
\hline 9 & 65.59 & 37325 & 41057 & $4.75 \mathrm{E}-03$ \\
\hline 10 & 103.91 & 40996 & 45095 & $9.49 \mathrm{E}-03$ \\
\hline & $\begin{array}{l}{[1]} \\
{[2]} \\
{[3]} \\
{[4]}\end{array}$ & $\begin{array}{l}\text { Estimated industry MC } \\
\text { Load } \\
\text { Load and reserves }=1.1 *[1] \\
([1]-[1](-1)) /([3]-[3](-1))\end{array}$ & & \\
\hline
\end{tabular}
hypothetical profits from unilateral withholding. 
The last table gives details of the calculation in Table 6 .

\begin{tabular}{|rrrrrrrrrr|}
\hline$p_{c}$ & $q_{c}$ & $q_{l}$ & $M C\left(q_{c}\right)$ & $M C\left(q_{l}\right)$ & $d p / d q$ & Revenue loss & Revenue gain & Cost savings & Total \\
\hline$[1]$ & {$[2]$} & {$[3]$} & {$[4]$} & {$[5]$} & {$[6]$} & {$[7]$} & {$[8]$} & {$[9]$} & {$[10]$} \\
60 & 3,000 & 1,500 & 55 & 50 & 0.011 & 90,000 & $25,714.29$ & 78,750 & $14,464.29$ \\
60 & 3,000 & 1,500 & 55 & 55 & 0.001 & 90,000 & $2,571.43$ & 82,500 & $-4,928.57$ \\
\hline$[7]$ & $=[1]^{*}([2]-[3])$ & & & & & & & \\
{$[8]$} & $=[6]^{*}([2]-[3]) *[3]$ & & & & & & & \\
{$[9]$} & $=\left(0.5^{*}[5]+0.5^{*}[4]\right) *([2]-[3])$ & & & & & & \\
{$[10]$} & $=[8]+[9]-[7]$
\end{tabular}

\section{E. RTC NOx Credit Prices}

A unique characteristic of the RTC program is that while allowances periodically expire, the settlement procedures in the program give NOx emitters up to two months following the close of the cycle period to reconcile RTC allowances with actual emissions. There is an active market in expired allowances during those two months. It is improper, however, to correlate current prices for electric power with price movements in expired allowances. Competitive prices will reflect the marginal costs of current inputs to current generation; competitive prices do not recoup unanticipated increases in sunk costs from past periods. We have therefore examined the prices of RTC NOX credits over the study period in two groups: prices for June are represented by June prices for RTCs expiring on June 30, 2000, and prices for the post-June period are represented by contemporaneous prices for RTCs expiring on December 31, 2000.

The main data issue for the SCAQMD's list of transactions at more that $\$ 4.00$ is that the date given for an observation is the "registration recording date" (rrd) not the date the transaction was executed or received by SCAQMD. We believe that the lag between the rrd and the "deal date" is about 1.5 weeks. It looks like almost all of the rrd's are either Tuesdays or Fridays plus there is a memo in the materials discussing the receipt of a transaction at $\$ 30$ on the 27 th of July. The rrd for this transaction is the 4th of August.

With that caveat, we reviewed transactions over time for RTCs both for the period ending 6/30/00 and for that ending 12/31/00. The graphs of these transactions by estimated date are shown below. On the basis of these data, we choose $\$ 10 / \mathrm{lb}$ as the June RTC price, $\$ 20 / \mathrm{lb}$ as the July price and $\$ 35 / \mathrm{lb}$ as the August and September prices. 

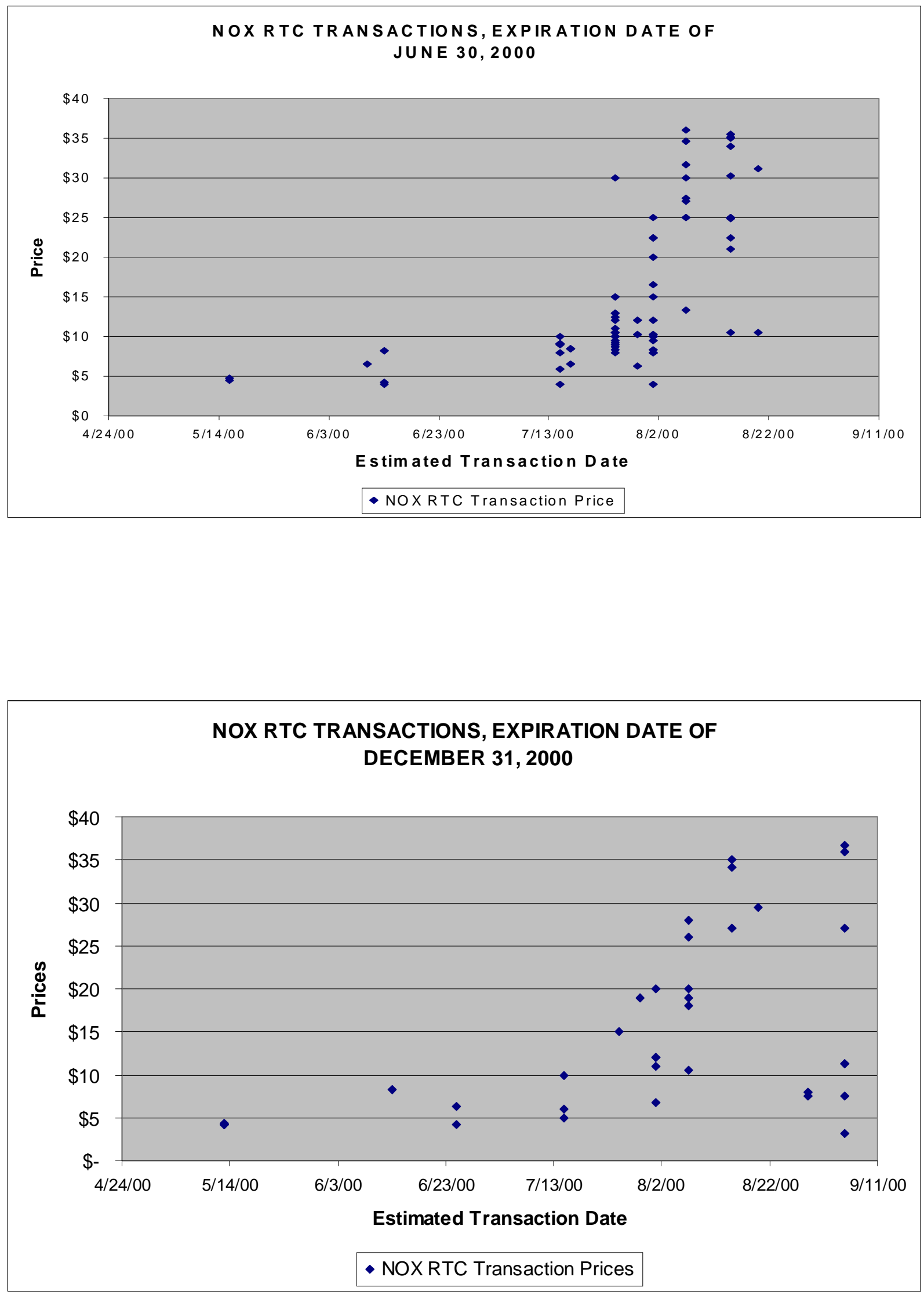